\begin{tabular}{|l|l|}
\hline $\begin{array}{l}\text { Postprint } \\
\text { Version }\end{array}$ & 1.0 \\
\hline Journal website & http://link.springer.com/article/10.1007\%2Fs00520-013-2019-9 \\
\hline Pubmed link & $\underline{\text { http://www.ncbi.nlm.nih.gov/pubmed/24146344 }}$ \\
\hline DOI & $10.1007 /$ s00520-013-2019-9 \\
\hline
\end{tabular}

This is a NIVEL certified Post Print, more info at http://www.nivel.eu

\title{
Reasons for hospitalisation at the end of life: differences between cancer and non-cancer patients
}

\author{
Maria C. De Korte-Verhoef, H. Roeline W. PAsman, BARt P. M. SchWeitzer, \\ ANNEKE L. FRANCKE, BREGJE D. ONWUTEAKA-PHILIPSEN, LUC DELIENS
}

\begin{abstract}
Purpose: Many patients are hospitalised during the final phase of life, even though most prefer to receive care at home until the end. This study aimed to explore the reasons and characteristics of hospitalisation in the final 3 months of life for patients who died non-suddenly, with a comparison between cancer patients and non-cancer patients.

Methods: This study used a nationwide retrospective cross-sectional survey among Dutch general practitioners.

Results: Of the 317 hospitalised patients, 65 \% had cancer. Most common reasons for hospitalisation in the final 3 months of life were respiratory symptoms (31\%), digestive symptoms (17\%), and cardiovascular symptoms (17\%). Seventy-three percent of patients experienced an acute episode before hospitalisation, and for $46 \%$ of patients, their own GP initiated the hospitalisation. Compared to non-cancer patients, cancer patients were significantly more likely to be aged less than 80 (81 versus $46 \%$ ), were more likely to be hospitalised because of digestive symptoms (22 versus $7 \%$ ), were less likely to have a curative treatment goal before the last hospitalisation (6 versus $22 \%$ ) and were less likely to die in hospital (22 versus 49 $\%)$.

Conclusions: Respiratory problems were the most common reasons for hospitalisation in the group of patients as a whole. Digestive problems were a frequent reason for hospitalisation in cancer patients and cardiovascular symptoms in non-cancer patients. Hospitalisation can therefore be anticipated by monitoring these relatively common symptoms. Also, timely communication with the patient is recommended about their preferences for hospital or home treatment in the case of an acute episode.
\end{abstract}

\section{INTRODUCTION}

Many patients are hospitalised during the final phase of life $\left[{ }^{1},{ }^{2}\right]$, even though most prefer to receive care at home $\left[{ }^{3}-5\right]$. The proportion of patients who are transferred 
from home to hospital in the last 3 months of life is $55 \%$ in the Netherlands and 60 $\%$ in Belgium $\left[{ }^{1},{ }^{2}\right]$. In Canada, $68 \%$ are transferred to hospital in the last 6 months of life $\left[{ }^{6}\right]$.

Factors associated with a greater likelihood of hospitalisation at the end of life include being male, multiple morbidity, infections and patients for whom there was no palliative-centred treatment goal or where the general practitioner (GP) was not aware of the patients' wishes concerning the place of death $\left[{ }^{1},{ }^{2}\right]$ The reasons most commonly given for the hospital referral of palliative care patients for whom an outof-hours GP cooperative was called were digestive problems, endocrine/metabolic/nutritional problems, and respiratory problems $\left[{ }^{7}\right]$. In addition, dyspnoea, pain, inability to cope at home and an altered level of consciousness were the most important reasons for the hospitalisation of lung cancer patients $\left[{ }^{8}\right]$.

As previous studies of the reasons for hospitalisation only included lung cancer patients or patients for whom an out-of-hours GP was called, more information was needed on the general group of patients who died non-suddenly. In addition, up to now, no information has been available on what occurred before or during hospitalisation, such as who initiated the hospitalisation, what the prognosis was just before hospitalisation, and what kind of treatments the patient received. It is important to look in more detail at the patients who are hospitalised and the characteristics of the final hospitalisation in order to understand more about hospitalisations at the end of life. This additional information might give more insight into whether hospitalisations could be avoided. This is relevant since most patients prefer to remain at home at the end of life $\left[{ }^{3}-{ }^{5}\right]$. In addition, hospitalisation can cause distress in patients and diminished continuity of care $\left[{ }^{9}\right]$.

Therefore, the aim of this study is to explore the reasons for and characteristics of the last hospitalisation in the final 3 months of life for patients who died non-suddenly. We compare cancer patients with non-cancer patients since it is known that the cancer disease trajectory at the end of life differs from non-cancer disease trajectories $\left[{ }^{10},{ }^{11}\right]$.

\section{METHOD}

\section{Design}

In 2011, a nationwide retrospective cross-sectional survey with a written questionnaire was conducted among Dutch GPs. In the questionnaire, we asked the GPs to recall their last deceased adult patient in the past year whose death was nonsudden and who was hospitalised in the last 3 months of life. Hospitalisation was defined as staying in a hospital for at least one night.

\section{Study population}

A random sample of 1,200 GPs was selected from the population of 8,896 registered GPs in the Dutch "Medical Address book" of 2010. Respondents had to be working as a GP in a GP practice at the time of data collection. Of the 1,200 GPs in the sample, 150 were not working as a GP when the questionnaire was sent and 100 did not have patients who met the criteria. This resulted in 950 eligible GPs, of whom 322 filled in the questionnaire (34 \%). In total, five GPs were excluded because they had not filled out the core questions about the reasons for hospitalisation and/or cause of death. This gave a net response of 317 questionnaires. 
In the Netherlands, GPs are responsible for palliative-care patients living at home, in homes for the elderly, and in inpatient hospice care, but not for patients being cared for in a nursing home. To support GPs, specialised palliative consultation teams in all Dutch regions are available.

\section{Measurements}

The written questionnaires were developed using relevant literature $\left[{ }^{1},{ }^{2},{ }^{7},{ }^{8}\right]$ and open interviews with five physicians. A draft of the questionnaire was tested among 14 GPs. Their comments were incorporated in the final version of the questionnaire. The questionnaire included closed questions about the patient's age, main treatment goal, prognosis just before hospitalisation, place of death, all diseases of the patient, the cause of death, and the number of hospitalisations in the last 3 months of life. The questionnaire also included one open question about the most important reason for the last hospitalisation. In addition, the characteristics of the last hospitalisation were asked in closed questions about the person who initiated the last hospitalisation, whether an acute episode and/or a diagnostic goal played a role in hospitalisation and the timing and duration of the last hospitalisation. There were also closed questions asking what treatments the patient received in the last 3 months of life, followed by an open question asking what treatments the patient received during the last hospitalisation.

\section{Analyses}

Analyses were performed for patients who died of cancer $(n=205)$ and patients who died of a non-cancer disease $(n=112)$. The most important reasons for hospitalisation were categorised into treatment, diagnostic, symptoms/complaints, and social reasons. The symptoms/complaints given as reasons for hospitalisation were labelled in accordance with the main categories and subcategories of the International Classification of Primary Care (ICPC-2) $\left[{ }^{12}\right]$.

Descriptive statistics were performed using SPSS 20. A Chi-square test or Fisher's exact test (for low numbers of observations) was used to assess the significance of differences between patients who died of cancer and patients who died of a noncancer disease.

\section{RESULTS}

\section{Characteristics of GPs and patients hospitalised in the final 3 months of life} The mean age of the GPs $(n=317)$ was 49 , with a range from 31 to $64,55 \%$ were male, $6 \%$ of GPs completed specialised education in palliative care and $46 \%$ worked in a highly urban environment.

Of all the patients who died non-suddenly and who were hospitalised in the final 3 months of life, $31 \%$ were 80 years or older, $57 \%$ were male, $51 \%$ had multimorbidity and $32 \%$ died in the hospital. Before hospitalisation, the main treatment goal for $80 \%$ of all patients was palliation or life prolonging and $40 \%$ had a predicted life expectancy of a few weeks or less (Table 1). Cancer patients were significantly more likely than non-cancer patients to be aged less than 80 (81 versus $47 \%$ ) and had a shorter life expectancy before hospitalisation. In addition, cancer patients were significantly less likely to have multimorbidity (39 versus $73 \%$ ), were less likely to have a curative treatment goal before hospitalisation (6 versus $22 \%$ ) and were less likely to die in hospital (22 versus $49 \%$ ) than cancer patients. In all, 6 $\%$ of patients died in an intensive care unit (not in Table). 
Korte-Verhoef, M.C. de, Pasman, H.R.W., Schweitzer, B.P.M., Francke, A.L., OnwuteakaPhilipsen, B.D., Deliens, L. Reasons for hospitalisation at the end of life: differences between cancer and non-cancer patients. Supportive Care in Cancer: 2014, 22(3), 645-652

\section{[TABLE 1]}

\section{Reasons for the last hospitalisation}

A total of 71 different most important reasons for the last hospitalisation were reported by the GPs. Two reasons were given for $18 \%$ of patients and three reasons for $6 \%$ as the most important for the last hospitalisation (not in Table). The reasons were categorised into symptoms/complaints (85\%), treatment (10\%), diagnostic (5 $\%$ ) and social reasons ( $4 \%$ ) (Table 2). Of all patients, most common reasons for hospitalisation were respiratory symptoms (31 \%), digestive symptoms (17 \%) and cardiovascular symptoms (17\%). Cancer patients were significantly more likely to be hospitalised because of digestive symptoms (22 versus $7 \%$ ), such as ileus, and for pain in general (9 versus $1 \%$ ) compared with non-cancer patients. In non-cancer patients, the most frequent reasons for hospitalisation were respiratory symptoms (48 versus $21 \%$ for cancer patients), such as dyspnoea and pneumonia, and cardiovascular complaints (29 versus $6 \%$ ), such as heart failure.

\section{[TABLE 2]}

\section{Characteristics of the last hospitalisation}

In general, hospitalisation was most likely to be initiated by the patient's own GP (46 \%) (Table 3). Even in acute episodes, the patient's own GP was involved for $44 \%$ of patients (not in Table). The hospitalisation of cancer patients was significantly less likely to be initiated by a locum (23 versus $38 \%$ ) and more likely to be initiated by the patient and/or family (13 versus $5 \%$ ) or the medical specialist (17 versus $6 \%$ ) compared with non-cancer patients. An acute episode played a role in the hospitalisation of $73 \%$ of all patients and a diagnostic goal played a role in the hospitalisation of $44 \%$ of patients. Patients experiencing an acute episode were significantly more likely to have respiratory symptoms (34 versus $21 \%$ ) and cardiovascular symptoms (17 versus $7 \%$ ) than patients in non acute episodes (not in Table). In all, $18 \%$ of patients received only pharmacological treatment, excluding chemotherapy or no treatment at all in the hospital; furthermore, no diagnostic goal played a role either in the hospitalisation of these patients (not in Table). Cancer patients were significantly more likely to receive medication for pain relief, chemotherapy, radiotherapy, and/or stent implementation and non-cancer patients were significantly more likely to receive pharmaceutical treatment, infusion therapy, antibiotics, oxygen delivery, diuretics and medication change. One third of all patients were hospitalised in the last week before death. A significantly higher proportion of cancer patients had a short stay in hospital of $1-2$ days (33 versus $15 \%$ of non-cancer patients).

\section{[TABLE 3]}

\section{DISCUSSION}

\section{Summary}

Of all patients who died non-suddenly and who were hospitalised in the last 3 months of life, $65 \%$ had cancer. Symptoms or complaints were mentioned in $85 \%$ of cases as the most important reason for hospitalisation, with respiratory, digestive, and cardiovascular symptoms being the most common. In about half of the cases, the 
patient's own GP initiated the hospitalisation and $73 \%$ of patients experienced an acute episode before hospitalisation. Compared to non-cancer patients, cancer patients were significantly more likely to be aged less than 80 , were more likely to have digestive symptoms as an important reason for hospitalisation, were more likely to have a short stay of less than 3 days in the hospital and were less likely to die in hospital. Non-cancer patients were more likely to have multimorbidity, were more likely to have respiratory symptoms and/or cardiovascular problems as the reason for hospitalisation, were more likely to have a curative treatment goal before the last hospitalisation and were more likely to receive antibiotics, oxygen and/or diuretics than cancer patients.

\section{Strengths and limitations}

The strength of this study is that data are included from both cancer patients and noncancer patients at the end of life of a GP practice. This study provides new insights into the reasons for hospitalisation and the characteristics of hospitalisations. Hence, it gives indications for GPs to anticipate most common symptoms in cancer and noncancer patients.

A limitation of the study is the low-response rate. However, the age, gender, and level of practice urbanisation of our study population do not differ from that of the general Dutch population of GPs $\left[{ }^{13},{ }^{14}\right]$. In addition, in our research, more respondents completed a specialised education in palliative care $(6 \%)$ than in the general population of Dutch GPs. However, for reasons and avoidability, we found no significant differences between the educated group and the non-educated group. Therefore, we think that the low-response rate of GPs has little or no effect on the generalisability.

A possible limitation of the study is that GPs were not fully informed about their patient's situation during the hospitalisation and all the treatments given, which may have led to an underestimation of hospital treatment.

\section{Comparison with existing literature}

\section{Palliative care}

The present study shows that a need for symptom relief is most likely to be the most important reason for hospitalisation in both cancer and non-cancer patients. As improving the quality of life through symptom relief is an important goal of palliative care, it seems that many of the hospitalisations at the end of life fit in with a palliative care approach $\left[{ }^{15}\right]$. This notion is further supported by the type of treatments patients received in hospital, such as antibiotics, oxygen delivery and diuretics to treat dyspnoea, pneumonia or heart failure, and by our finding, that cure was still the main treatment goal for only $11 \%$ of patients before the last hospitalisation. However, it can be questioned whether the hospitalisations were necessary in all cases. Other studies indicate inappropriate hospitalisations or aggressive care at the end of life $\left[{ }^{8},{ }^{16},{ }^{17}\right]$. Walsh et al. $\left[{ }^{18}\right]$ suggest that these conditions could often be managed outside the hospital, particularly in the case of patients with pneumonia, congestive heart failure, urinary tract infections, dehydration and chronic obstructive pulmonary disease. In addition, low levels of hospitalisation for the population as a whole are considered to be a quality indicator of good palliative care $\left[{ }^{19}\right]$. 
An explanation for patients being hospitalised rather than staying at home in the last phase of life might be found in our finding that hospitalisation took place in an acute episode in $73 \%$ of cases. Acute episodes can be expected at the end of life and therefore it is recommended to anticipate patients' needs $\left[{ }^{20}\right]$. Ways of anticipating that can be successful in reducing hospitalisations are the availability of appropriate "as needed" medication to be used in acute episodes at home $\left[{ }^{21}\right]$, information transfer from GPs to the out-of-hours general practice and the monitoring of symptoms and timely discussions with the patient/family about their preferences and what can happen at the end of life $\left[{ }^{22}{ }^{24}\right]$.

\section{Illness trajectories}

This study compared the hospitalisation of cancer patients with that of non-cancer patients. It enables us to relate our results to the different illness trajectories described by Lynn and Adamson $\left[{ }^{10}\right]$ and Murray et al. $\left[{ }^{11}\right]$. Firstly, they distinguished a common cancer end-of-life trajectory characterised by a period of relatively good functioning with a rapid and reasonably predictable decline in clinical status and a foreseen death. Secondly, two trajectories were distinguished for noncancer patients: a trajectory for patients with organ failure such as COPD and heart failure, and a trajectory for frail patients, such as dementia patients. Both illness trajectories are characterised by a slow functional decline, which may end in an acute event. The acute event for patients with an organ disease often concerns an acute exacerbation. For frail patients, the acute event often concerns pneumonia $\left[{ }^{10},{ }^{11}\right]$ With these common illness trajectories in mind, one would expect that compared with non-cancer patients, cancer patients would be less likely to have a curative treatment goal. In relation to this, one would also expect that the approaching death is more likely to be foreseen in cancer patients. Our results do indeed point in this direction: $6 \%$ of the cancer patients had a curative treatment goal versus $22 \%$ of the non-cancer patients, and at the time of the last hospitalisation, the predicted life expectancy was a few weeks or less for $50 \%$ of cancer patients as opposed to $22 \%$ of non-cancer patients. The fact that the approach of death is more difficult to foresee in non-cancer patients may hamper a timely start to palliative care in this group. Other studies also indicate that it is difficult to identify when palliative care starts for non-cancer patients $\left[{ }^{25}{ }^{27}\right]$. Therefore, more education and research is needed to identify when palliative care starts in non-cancer patients. With the more predictable cancer trajectory in mind, one would also expect that hospitalisation in cancer patients would be less likely to involve an acute episode. However, we did not find this in our study, suggesting the need for better anticipation in all patients in the last phase of life.

\section{Implications for research and practice}

It is important for professionals to understand the main reasons and characteristics of hospitalisations at the end of life and the differences between cancer and non-cancer patients in order to reduce hospitalisations at the end of life. Anticipating hospitalisations requires monitoring of common symptoms, such as respiratory problems in all patients and digestive problems in cancer patients. In addition, it is important to have timely discussions with the patient and family about the preferences for hospital or home treatment in the case of acute episodes. Further studies are needed on effective ways to anticipate evolving and increasing symptoms 
Korte-Verhoef, M.C. de, Pasman, H.R.W., Schweitzer, B.P.M., Francke, A.L., OnwuteakaPhilipsen, B.D., Deliens, L. Reasons for hospitalisation at the end of life: differences between cancer and non-cancer patients. Supportive Care in Cancer: 2014, 22(3), 645-652

early in the disease trajectory to avoid acute episodes and hence reduce hospitalisations at the end of life.

\section{Acknowledgments}

This study is funded by ZonMw, the Netherlands Organization for Health Research and Development. We thank the GPs for taking time to fill in the questionnaire.

\section{Conflict of interest statement}

The authors declare that there were no conflicts of interest in preparing this study and they have full control of all primary data. We allow the journal to review the data if requested.

\section{REFERENCES}

1. Abarshi E, Echteld M, Van den Bock L, Donker G, Deliens L, Onwuteaka-Philipsen B (2010) Transitions between care settings at the end of life in the Netherlands: results from a nationwide study. Palliat Med 24(2):166-174. doi:10.1177/0269216309351381

2. Van den Block L, Deschepper R, Drieskens K, Bauwens S, Bilsen J, Bossuyt N, Deliens L (2007) Hospitalisations at the end of life: using a sentinel surveillance network to study hospital use and associated patient, disease and healthcare factors. BMC Health Serv Res 7:69. doi:10.1186/1472-6963-7-69

3. Gomes B, Higginson IJ, Calanzani N, Cohen J, Deliens L, Daveson BA et al (2012) Preferences for place of death if faced with advanced cancer: a population survey in England, Flanders, Germany, Italy, the Netherlands, Portugal and Spain. Ann Oncol 23(8):2006-2015. doi:10.1093/annonc/mdr602

4. Stajduhar KI, Allan DE, Cohen SR, Heyland DK (2008) Preferences for location of death of seriously ill hospitalized patients: perspectives from Canadian patients and their family caregivers. Palliat Med 22(1):85-88. doi:10.1177/0269216307084612

5. Choi J, Miyashita M, Hirai K, Sato K, Morita T, Tsuneto S, Shima Y (2010) Preference of place for end-of-life cancer care and death among bereaved Japanese families who experienced home hospice care and death of a loved one. Support Care Cancer 18(11):1445-1453. doi:10.1007/s00520-009-0767-3

6. Lawson B, Burge FI, Critchley P, McIntyre P (2006) Factors associated with multiple transitions in care during the end of life following enrollment in a comprehensive palliative care program. BMC Palliat Care 5:4. doi:10.1186/1472-684X-5-4

7. De Korte-Verhoef MC, Pasman HR, Schweitzer BP, Francke AL, Onwuteaka-Philipsen BD, Deliens L (2012) End-of-life hospital referrals by out-of-hours general practitioners: a retrospective chart study. BMC Fam Pract 13(1):89. doi:10.1186/1471-2296-13-89

8. Barbera L, Paszat L, Qiu F (2008) End-of-life care in lung cancer patients in Ontario: aggressiveness of care in the population and a description of hospital admissions. J Pain Symptom Manage Mar 35(3):267-274. doi:10.1016/j.jpainsymman.2007.04.019

9. Hanratty B, Holmes L, Lowson E, Grande G, Addington-Hall J, Payne S et al (2012) Older adults' experiences of transitions between care settings at the end of life in England: a qualitative interview study. J Pain Symptom Manage Jul 44(1):74-83. doi:10.1016/j. jpainsymman.2011.08.006

10. Lynn J, Adamson DM (2003) Living well at the end of life; adapting health care to serious chronic illness in old age. RAND, Santa Monica

11. Murray SA, Kendall M, Boyd K, Sheikh A (2005) Illness trajectories and palliative care. BMJ 330(7498):1007-1011

12. WONCA International Classification Committee (2005) ICPC-2-R:International classification of primary care, 2nd edn. Oxford University Press, Oxford

13. Hingstman L, Kenes RJ (2012) Cijfers uit de registratie van huisartsen, peiling 2011.

(Numbers of the registration of General Practitioners 2011) Utrecht, NIVEL

14. Nivel http://www.nivel.nl/databank. Accessed 23 Sept 2013

15. WHO http://www.who.int/cancer/palliative/definition/en/. Accessed 2 Jul 2013 
Korte-Verhoef, M.C. de, Pasman, H.R.W., Schweitzer, B.P.M., Francke, A.L., OnwuteakaPhilipsen, B.D., Deliens, L. Reasons for hospitalisation at the end of life: differences between cancer and non-cancer patients. Supportive Care in Cancer: 2014, 22(3), 645-652

16. Abel J, Rich A, Griffin T, Purdy S (2009) End-of-life care in hospital: a descriptive study of all inpatient deaths in 1 year. Palliat Med 23(7):616-622. doi:10.1177/ 0269216309106460

17. Gott M, Frey R, Robinson J, Boyd M, O'Callaghan A, Richards N, Snow B (2013) The nature of, and reasons for, 'inappropriate' hospitalisations among patients with palliative care needs: a qualitative exploration of the views of generalist palliative care providers. Palliat Med 27(8):747-756

18. Walsh EG, Wiener JM, Haber S, Bragg A, Freiman M, Ouslander JG (2012) Potentially avoidable hospitalizations of dually eligible Medicare and Medicaid beneficiaries from nursing facility and home- and community-based services waiver programs. J Am Geriatr Soc 60(5):821-829. doi:10.1111/j.1532-5415.2012.03920.x

19. De Roo ML, Leemans K, Claessen SJJ, Cohen J, Pasman HRW, Deliens L, Francke AL (2013) Quality indicators for palliative care: update of a systematic review. J Pain Symptom Manage. doi:10.1016/j.jpainsymman.2012.09.013

20. NHS National Institute for Health and Clinical Exellence (2011) Information for adults who use NHS end of life care services and their families and carers; NICE quality standard

21. Wowchuk SM, Wilson EA, Embleton L, Garcia M, Harlos M, Chochinov HM (2009) The palliative medication kit: an effective way of extending care in the home for patients nearing death. J Palliat Med 12(9):797-803. doi:10.1089=jpm.2009.0048

22. Schweitzer BP, Blankenstein N, Deliens L, van der Horst H (2009) Out-of-hours palliative care provided by GP co-operatives: availability, content and effect of transferred information. BMC Palliat Care 8:17. doi:10.1186/1472-684X-8-17

23. Brumley R, Enguidanos S, Jamison P, Seitz R, Morgenstern N, Saito S et al (2007) Increased satisfaction with care and lower costs: results of a randomized trial of in-home palliative care. J Am Geriatr Soc 55(7):993-1000. doi:10.1111/j.1532-5415.2007.01234.x

24. Wright AA, Zhang B, Ray A, Mack JW, Trice E, Balboni T, Trice E et al (2008) Associations between end-of-life discussions, patient mental health, medical care near death, and caregiver bereavement adjustment. JAMA 300(14):1665-1673. doi:10.1001/ jama.300.14.1665

25. Abarshi EA, Echteld MA, Van den Block L, Donker GA, Deliens L, Onwuteaka-Philipsen BD (2011) Recognising patients who will die in the near future: a nationwide study via the Dutch Sentinel Network of GPs. Br J Gen Pract 61(587):e371-e378. doi:10.3399/ bjgp11X578052

26. Thoonsen B, Groot M, Engels Y, Prins J, Verhagen S, Galesloot C et al (2011) Early identification of and proactive palliative care for patients in general practice, incentive and methods of a randomized controlled trial. BMC Fam Pract 12:123. doi:10.1186/1471-229612-123.:123-12

27. Claessen SJ, Francke AL, Engels Y, Deliens L (2013) How do GPs identify a need for palliative care in their patients? An interview study. BMC Fam Pract 14(1):42. doi:10.1186/ 1471-2296-14-42 
Korte-Verhoef, M.C. de, Pasman, H.R.W., Schweitzer, B.P.M., Francke, A.L., OnwuteakaPhilipsen, B.D., Deliens, L. Reasons for hospitalisation at the end of life: differences between cancer and non-cancer patients. Supportive Care in Cancer: 2014, 22(3), 645-652

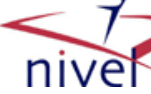

\section{TABLES}

Table 1 Characteristics of hospitalised patients in the final 3 months of life and differences between patients who died of cancer and patients who died of a non-cancer disease $(n=317)$

*Types of cancer:

gastroenterological (33\%), lung (31\%), prostate $(10 \%)$, breast $(6 \%)$ or other $(21 \%)$

***Types of non-cancer diseases: cardiovascular $(43 \%)$, respiratory (30\%), old age/dementia/ deterioration ( $8 \%)$, stroke $(6 \%)$, kidney disease $(5 \%)$ or other diseases $(8 \%)$

\begin{tabular}{|c|c|c|c|c|}
\hline & Total $(\%)$ & $\begin{array}{l}\text { Died of cancer* } \\
(n=205)(\%)\end{array}$ & $\begin{array}{l}\text { Died of non-cancer } \\
\text { disease** }(n=112)(\%)\end{array}$ & $P$ value \\
\hline \multicolumn{4}{|l|}{ Age } & \multirow[t]{4}{*}{$<0.001$} \\
\hline$<65$ & 30 & 41 & 10 & \\
\hline $65-79$ & 39 & 40 & 37 & \\
\hline$\geq 80$ & 31 & 19 & 54 & \\
\hline \multicolumn{5}{|l|}{ Gender } \\
\hline Male & 57 & 55 & 60 & 0.399 \\
\hline \multicolumn{5}{|l|}{ Multimorbidity } \\
\hline Two diseases & 28 & 23 & 37 & 0.012 \\
\hline Three or more diseases & 23 & 16 & 36 & $<0.001$ \\
\hline \multicolumn{5}{|c|}{ Main treatment aim before the last hospitalisation } \\
\hline Diagnosis was unknown & 9 & 8 & 12 & 0.292 \\
\hline Palliation & 57 & 60 & 51 & 0.121 \\
\hline Life prolonging & 23 & 26 & 16 & 0.04 \\
\hline Cure & 11 & 6 & 22 & $<0.001$ \\
\hline \multicolumn{4}{|c|}{ Prognosis before the last hospitalisation } & \multirow[t]{7}{*}{$<0.001$} \\
\hline A few days & 7 & 8 & 6 & \\
\hline A few weeks & 33 & 42 & 16 & \\
\hline A few months & 44 & 41 & 49 & \\
\hline A few years & 10 & 3 & 22 & \\
\hline Cure expected & 3 & 2 & 5 & \\
\hline Unknown & 4 & 4 & 2 & \\
\hline \multicolumn{5}{|l|}{ Place of death } \\
\hline Hospital & 32 & 22 & 49 & $<0.001$ \\
\hline \multicolumn{4}{|c|}{ Number of hospitalisations in the final 3 months of life } & \multirow[t]{4}{*}{0.018} \\
\hline 1 & 54 & 51 & 61 & \\
\hline 2 & 26 & 25 & 30 & \\
\hline$>2$ & 20 & 25 & 12 & \\
\hline
\end{tabular}


Korte-Verhoef, M.C. de, Pasman, H.R.W., Schweitzer, B.P.M., Francke, A.L., OnwuteakaPhilipsen, B.D., Deliens, L. Reasons for hospitalisation at the end of life: differences between cancer and non-cancer patients. Supportive Care in Cancer: 2014, 22(3), 645-652

Table 2 Most important reasons for the last hospitalisation in the final 3 months of life according to the GP and differences between cancer and non-cancer patients $(n=317)$

*Reasons are presented in the table if they were noted in total for more than $2 \%$ of the sample

**Categorised according the International Classification of Primary Care (ICPC)

\begin{tabular}{|c|c|c|c|c|}
\hline Reasons for hospitalisation* & Total (\%) & $\begin{array}{l}\text { Died of cancer } \\
(n=205)(\%)\end{array}$ & $\begin{array}{l}\text { Died of non-cancer } \\
\text { disease }(n=112) \\
(\%)\end{array}$ & $P$ value \\
\hline Treatment & 10 & 13 & 3 & 0.002 \\
\hline Chemotherapy & 3 & 4 & 0 & 0.029 \\
\hline Other treatment reasons & 7 & 9 & 3 & 0.037 \\
\hline Diagnostic & 5 & 8 & 1 & 0.009 \\
\hline Symptoms/complaints** & 85 & 78 & 97 & $<0.001$ \\
\hline Respiratory & 31 & 21 & 48 & $<0.001$ \\
\hline Dyspnoea & 24 & 16 & 39 & $<0.001$ \\
\hline Pneumonia & 6 & 3 & 13 & 0.001 \\
\hline Respiratory, other & 3 & 3 & 3 & 0.720 \\
\hline Digestive & 17 & 22 & 7 & 0.001 \\
\hline Ileus & 5 & 8 & 0 & 0.002 \\
\hline Abdominal pain & 4 & 4 & 5 & 1 \\
\hline Vomiting/nausea & 3 & 4 & 1 & 0.105 \\
\hline $\begin{array}{l}\text { Digestive bleeding (melaena, } \\
\text { stomach or rectal bleeding) }\end{array}$ & 3 & 3 & 2 & 0.717 \\
\hline Digestive, other & 3 & 3 & 1 & 0.268 \\
\hline Cardiovascular & 14 & 6 & 29 & $<0.001$ \\
\hline Heart failure & 10 & 3 & 21 & $<0.001$ \\
\hline Pulmonary or deep venous embolism & 2 & 2 & 3 & 0.669 \\
\hline Cerebrovascular accident & 2 & 1 & 4 & 0.190 \\
\hline Cardiovascular, other & 1 & 1 & 2 & 0.286 \\
\hline Endocrine, metabolic or nutritional & 8 & 7 & 9 & 0.611 \\
\hline Dehydration & 3 & 2 & 5 & 0.175 \\
\hline Ascites & 3 & 3 & 1 & 0.268 \\
\hline Endocrine, metabolic or nutritional, other & 2 & 2 & 3 & 0.701 \\
\hline \multicolumn{5}{|l|}{ General } \\
\hline Pain & 6 & 9 & 1 & 0.005 \\
\hline Weakness/malaise & 5 & 6 & 3 & 0.203 \\
\hline Deterioration & 4 & 3 & 5 & 0.393 \\
\hline Fever & 2 & 3 & 0 & 0.093 \\
\hline Psychological & 4 & 3 & 5 & 0.393 \\
\hline Delirium & 3 & 2 & 5 & 0.332 \\
\hline Psychological, other & 1 & 1 & 1 & 1 \\
\hline Musculoskeletal: fracture & 4 & 3 & 5 & 0.760 \\
\hline Urinary & 5 & 4 & 6 & 0.470 \\
\hline Neurological & 4 & 6 & 2 & 0.150 \\
\hline Blood problems (e.g. anaemia) & 2 & 2 & 2 & 1 \\
\hline Social family reasons & 4 & 4 & 3 & 0.752 \\
\hline
\end{tabular}


Korte-Verhoef, M.C. de, Pasman, H.R.W., Schweitzer, B.P.M., Francke, A.L., OnwuteakaPhilipsen, B.D., Deliens, L. Reasons for hospitalisation at the end of life: differences between cancer and non-cancer patients. Supportive Care in Cancer: 2014, 22(3), 645-652

Table 3 Characteristics of the last hospitalisation in the final 3 months of life and differences between patients who died of cancer and patients who died of non-cancer disease $(n=317)$

* More than one answer could be given

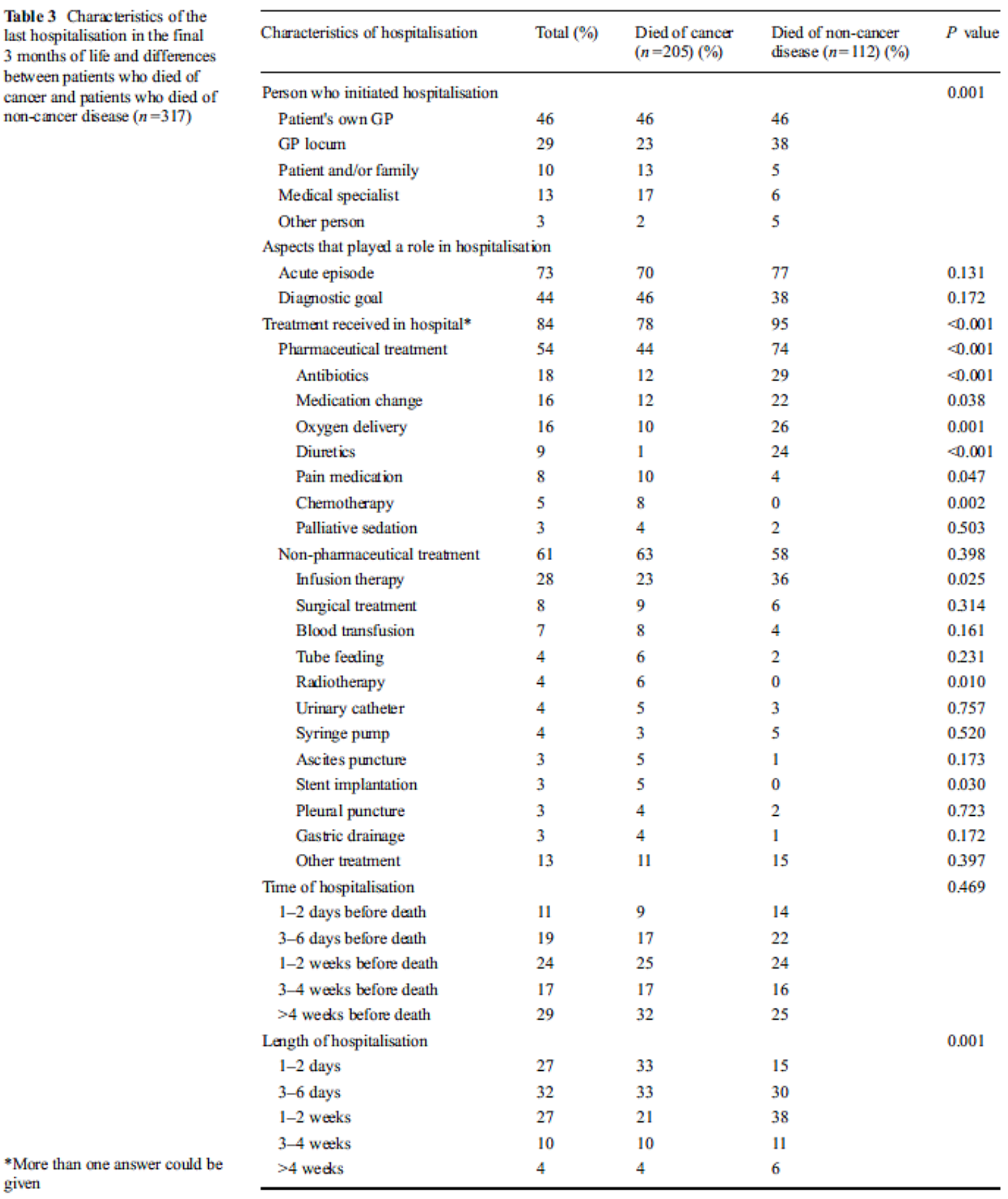

